\title{
A PERCEPÇÃO DE EGRESSOS SOBRE OS PROCESSOS FORMATIVOS DESENVOLVIDOS NO ENSINO FUNDAMENTAL DE ESCOLAS WALDORF
}

\author{
The Perception of Former Students Regarding the LEARNING PROCESSES \\ DEVELOPED IN WALDORF PRIMARY SCHOOLS
}

\section{La Percepción de Antiguos aluminos sobre los procesos de Formación DESARROLLADOS EN ESCUELAS PRIMARIAS DE PEDAGOGÍA WALDORF}

\author{
Eliane Souza Oliveira dos \\ Santos \\ (iD) 9 \\ Mestrado em Ciências da \\ Motricidade Humana (Unesp/Rio \\ Claro/SP) \\ Professora na Universidade \\ Federal de Mato Grosso (Campus \\ Cuiabá) \\ Discente no Programa de Pós- \\ Graduação em Educação - Nível \\ Doutorado (PPGE/IE/UFMT) \\ elianefefufmt@gmail.com
}

\section{Cleomar Ferreira Gomes (iD) 9}

Doutorado em Educação (USP/SP)

Professor na Universidade Federal

de Mato Grosso (Campus Cuiabá)

Docente no Programa de Pós-

Graduação em Educação - Nível

Doutorado (PPGE/IE/UFMT)

gomescleo.cg@gmail.com

\begin{abstract}
Resumo
A singularidade da formação da Pedagogia Waldorf (PW) ainda é mitificada. Assim, objetivou-se com esta pesquisa identificar a percepção de Egressos do Ensino Fundamental (EEF) quanto aos processos formativos desenvolvidos na $\mathrm{PW}$, recorrendo-se à pesquisa qualitativa-descritiva com o uso do questionário aplicado no período de 2019 e 2020 a 28 egressos cuja idade varia entre 14 e 18 anos. Oriundos da referida pedagogia, os egressos que, atualmente, cursam o Ensino Médio (EM) em escola não Waldorf avaliaram positivamente a formação que tiveram na PW, especialmente devido à base sólida proporcionada em diferentes áreas que consideram valiosas para o seu processo de desenvolvimento ao longo da vida. Os EEF apresentaram como principais motivos os processos de ensino e aprendizagem, o papel do professor, as relações sociais e a formação humanizante e integradora. Apesar de manifestarem favoráveis à PW, alguns egressos consideram essa pedagogia mais apropriada ao nível Fundamental.

Palavras-chave: Pedagogia Waldorf; Ensino Fundamental; Egressos.
\end{abstract}

Recebido em: 6 de maio de 2021 .

Aprovado em: 16 de junho de 2021.

Como citar esse artigo (ABNT):

SANTOS, Eliane Souza Oliveira dos; GOMES, Cleomar Ferreira. A percepção de egressos sobre os processos formativos desenvolvidos no Ensino Fundamental de escolas Waldorf. Revista Prática Docente, v. 6, n. 2, e045, 2021. http://doi.org/10.23926/RPD.2021.v6.n2.e045.id1157 


\section{Abstract}

The singularity of the Waldorf Pedagogy (WP) education is still mythicized. Thus, in this research we aimed to identify the perception of former primary school students (FPSS) regarding the learning processes in the WP. This qualitative description study utilized a questionnaire applied in 2019 and 2020 to 28 former Waldorf students aged between 14 and 18 years old. These students, who are now in a non-Waldorf Education high school (HS), positively assess the education they had with the WP, especially the solid base carried out in different areas considered lifelong valuable. The FPSS presented, as their main reasons, the teaching and learning processes, the role of the teacher, the social relations and the compassionate and integrative education. Although they are favorable to the Waldorf Pedagogy, some former students consider this pedagogy more appropriate to primary school.

Keywords: Waldorf Pedagogy; Primary School; Former Students.

\section{Resumen}

La singularidad de la formación de la Pedagogía Waldorf (PW) es todavía mitificada. De este modo, objetivamos con esta investigación identificar la percepción de antiguos alumnos de la escuela primaria (AAEP) sobre los procesos de formación desarrollados en la PW. Recorrimos a una investigación descriptiva cualitativa y utilizamos un cuestionario aplicado en 2019 y 2020 a 28 antiguos alumnos de esa misma pedagogía entre 14 y 18 años. Eses alumnos, que ahora estudian en una escuela secundaria no Waldorf, evalúan positivamente la formación que tuvieron en la PW, especialmente debido a la base sólida ofrecida en áreas que consideran valiosas a lo largo de sus vidas. Los AAEP presentaron como principales razones los procesos de enseñanza y aprendizaje, el rol del profesor, las relaciones sociales y la formación que humaniza e integra. A pesar de favorables a la metodología, algunos alumnos consideran esa pedagogía más apropiada a la escuela primaria.

Palabras clave: Pedagogía Waldorf; Escuela Primaria; Antiguos Alumnos. 


\section{INTRODUÇÃ̃o}

Em um mundo globalizado e tecnológico, caracterizado por uma época de mudanças aceleradas intensas e externas, a Pedagogia Waldorf (PW) se apresenta, entre outras concepções pedagógicas, como uma possibilidade diferenciada de educação, tendo em vista seus fundamentos, estruturação curricular, metodológica e didática, bem como seu modo de gestão. Vale considerar, inicialmente, que a PW adota uma abordagem artístico-educativa, cuja finalidade consiste em promover uma formação humanística e integradora.

Algumas famílias, providas de melhores recursos financeiros, optam por escolas que adotam concepções pedagógicas que escapam do modelo tradicional, como a PW. Entretanto, sabe-se que o número desses estabelecimentos, predominantemente privados, ainda é restrito no Brasil, limitando, assim, o acesso à maior parte da população brasileira à PW. Além desse fator, a pouca divulgação da proposta metodológica inviabiliza que mais pessoas tenham conhecimento da PW.

A PW foi elaborada e desenvolvida na segunda década do século XX por Rudolf Steiner (1861-1925), com intuito de transformar a sociedade alemã no pós-guerra, tem como pano de fundo a Antroposofia. Trata-se, portanto, de uma proposta pedagógica com mais de cem anos de existência, a qual vem experimentando grande expansão no Brasil e no mundo. Em nosso país, a PW atende mais de 17.000 crianças e jovens da Educação Básica. Nesse universo, as escolas de Educação Infantil (EI) representam mais da metade das escolas Waldorf, enquanto as de nível médio, bastante reduzidas, perfazem somente $6 \%$ do total dessas instituições de ensino (FEWB, 2020).

Sobre a realidade brasileira, existem, aproximadamente, 265 escolas que adotam a PW, das quais 91 estão vinculadas à Federação das Escolas Waldorf no Brasil (FEWB) ${ }^{1}$. Comumente, as escolas iniciam pela oferta da EI, sendo que algumas permanecem ofertando apenas esse nível de ensino, e são poucas que chegam a ofertar o Ensino Médio (EM). Do total de escolas, 184 escolas ofertam exclusivamente a EI; 50 EI e Fundamental I, até o 5 ano; 17 oferecem Infantil, Fundamental I e II até o 9 ano, e somente 14 escolas possuem todos os níveis de ensino da Educação Básica, até o EM (FEWB, 2020).

\footnotetext{
${ }^{1}$ A FEWB foi fundada em 1998 e tem missão "Promover, fortalecer, defender e zelar pela essência e os interesses da Pedagogia Waldorf (PW) em todo o Brasil, em conjunto com a Seção Pedagógica no Brasil (SAB - Sociedade Antroposófica Brasileira), apoiando, orientando e representando as escolas associadas em seus processos de autonomia e qualidade pedagógica [...]" (FEWB, 2020). Disponível em: http://www.fewb.org.br/sobre desafios.html. Acesso em: 03 mar. 2021.
} 
Pesquisas foram desenvolvidas com estudantes egressos das escolas Waldorf com o intento de acompanhar o desenvolvimento dos alunos, a fim de, principalmente, desvelar alguns equívocos e intepretações errôneas que ainda cercam a metodologia (AZEVEDO; OLIVEIRA, 2018; BACH JÚNIOR, 2016; BACH JÚNIOR; GUERRA, 2018; BARZ; RANDOLL, 2007; GERWIN; MITCHELL, 2007; PACÍFICO; MARCONDES, 2016; PILONI, 2008; RIBEIRO; PEREIRA, 2007; SETZER, 2017). Vale destacar que a maioria dos estudos com egressos Waldorf aconteceu em outros países, cujo diálogo envolveu a formação e carreira profissional, religiosidade, estilo de vida e visão de mundo.

Diante das peculiaridades filosóficas e didático-metodológicas inerentes à PW e da carência de estudos brasileiros, aliado ao fato de os educandos serem impelidos a trocar de escola, ora pela escassez de estabelecimentos de EM que adotam a PW, ora pela apreensão quanto à competitividade para o ingresso no ensino superior brasileiro, levantaram-se as seguintes questões: Como os estudantes que concluíram o Ensino Fundamental (EF) em escola que adota a PW e estão inseridos em outra metodologia de ensino compreendem a formação recebida no EF? Quais aspectos inerentes ao sistema de ensino Waldorf são valorizados ou depreciados pelos egressos na formação recebida?

A fim de responder a essas questões, esta pesquisa teve o objetivo de identificar a percepção de Egressos do Ensino Fundamental (EEF) quanto aos processos formativos oriundos da PW. Trata-se, portanto de uma pesquisa que se faz relevante, em virtude de o aluno egresso se apresentar como fonte primordial para gerar dados que possibilitem melhor compreensão da PW. Assim, o ponto de vista de estudantes que já concluíram o EF em escola Waldorf e que estão completando sua escolarização básica em escolas que adotam o modelo tradicional pode revelar impressões, sensações e opiniões ainda presentes sobre a formação recebida no EF. Ademais, os egressos podem também dispor de mais elementos para observar as diferenças, dificuldades e facilidades, ou seja, as demandas encontradas no EM.

Nesta pesquisa, pretendemos colaborar com o processo reflexivo no campo educativo em uma temática pouco tratada. As escolas Waldorf apresentam singularidades que convergem, complementam ou coincidem com outras linhas pedagógicas as quais buscam novos modos de ensinar e aprender. Nessa perspectiva, as escolas Waldorf se ocupam e se preocupam com a melhoria das relações educativas, com a aproximação entre razão e emoção, mediante conhecimento integrado. São abordagens que almejam ambientes escolares mais humanizantes, cooperativos, de gestão democrática e participativa nos quais o protagonista seja o aluno, e a 
sala de aula seja um espaço de diálogo e pesquisa, ambiente estimulante para a formação livre, criativa, crítica e responsável.

A partir desse preâmbulo, apresentaremos a seguir o referencial teórico da PW e os resultados de pesquisas desenvolvidas com egressos.

\section{Pedagogia Waldorf}

\subsection{ASPECTOS HISTÓRICOS, FILOSÓFICOS E DIDÁtICOS-METODOLÓGICOS DA}

\section{Pedagogia Waldorf}

Ancorados nas obras de Rudolf Steiner ${ }^{2}$ e Rudolf Lanz $^{3}$, será apresentado de modo conciso a contextualização histórica, seguida de noções dos princípios e fundamentos dos aspectos metodológicos e didáticos da PW. A pedido de membros da Sociedade Antroposófica, Rudolf Steiner proferiu palestras sobre a trimembração social ${ }^{4}$ em Stuttgart (Alemanha), após a primeira guerra mundial. Essas palestras, que formam o conteúdo do livro "Os pontos centrais da questão social", oportunizaram ao então conselheiro de uma fábrica alemã de cigarros (Waldorf-Astoria) amadurecer a decisão de fundar uma escola para os filhos dos operários, visando que geminassem os fundamentos da Antroposofia ${ }^{5}$. Em 07 de setembro de 1919, Steiner aceitou, então, o convite do industrial Emil Molt para assumir a fundação e direção da primeira escola Waldorf, chamada por ele de Escola Livre, ancorada na Antroposofia (STEINER, 2018a).

A Antroposofia ou Ciência Espiritual Antroposófica busca ampliar nosso campo de observação. Lanz (2005, p. 16) apregoa que é “[...] uma ciência do Cosmo, tendo por centro e ponto de apoio o homem”. Segundo esse autor, “[...] procede cientificamente pela observação,

\footnotetext{
${ }^{2}$ Rudolf Steiner (1861-1925) viveu parte da infância e da juventude na Áustria. Ministrou aulas e atuou como professor particular. Desenvolveu estudo aprofundado sobre Goethe e Friedrich Schiller. Doutorou-se em Filosofia (1891-Alemanha). Foi estudioso da Teosofia e fundador da Sociedade Antroposófica (1913). Steiner foi editor de revista e proferiu mais de 6000 palestras por toda a Europa, a maioria sobre temas relativos a Antroposofia (SAB, 2020). Disponível em: http://www.sab.org.br/portal/antroposofia/sobre-rudolf-steiner/biografia-de-rudolf-steiner ${ }^{3}$ Rudolf Lanz (1915-1998) nasceu em Budapeste e emigrou para o Brasil em 1938. Foi o primeiro a se dedicar à introdução e divulgação da Antroposofia no país. Participou da fundação da primeira escola Waldorf (1956). Atuou como presidente da Associação Pedagógica Rudolf Steiner (1959-1981) e da Sociedade Antroposófica (19821995). Informações mais detalhadas estão disponíveis no portal da SAB. Disponível em http://www.sab.org.br/portal/antroposofia/no-brasil/biografias-de-destaque-no-brasil/99-rudolf-lanz.

${ }^{4}$ A Trimembração do Organismo Social, divulgado por Rudolf Steiner, revaloriza os impulsos da Revolução Francesa. Steiner concebeu a Liberdade como o princípio básico que deve reger a vida cultural-espiritual; a Igualdade como alicerce fundamental da questão jurídico-legal e a Fraternidade como sustentação imprescindível à atividade econômica (FEWB, 2020). Disponível em: http://www.fewb.org.br/pw fontes historicas.html

5 Antroposofia, é uma palavra de origem grega e significa "conhecimento do ser humano". Disponível em: http://www.sab.org.br/portal/antroposofia/o-que-e-antroposofia
} 
descrição e interpretação dos fatos. [...] Com efeito, ela admite e reconhece todas as descobertas das ciências naturais comuns, embora as complete e interprete com suas descobertas". A partir desses estudos, emergiram fundamentos para iniciativas sociais em diferentes áreas: agricultura, medicina, farmacologia e na educação por meio da PW (FEWB, 2020).

A concepção de Steiner (2018a) transmutou a visão de educação vigente na época ao abranger a dimensão espiritual. Segundo ele, a arte de educar deve ser construída sob o conhecimento plurilateral do ser humano corpóreo-anímico-espiritual, a fim de se obter uma atenta formação da consciência mediante conhecimento vivo do ser humano e do mundo que o cerca. Assim, a escola Waldorf deveria ser uma ação cultural cuja finalidade seria promover uma grande transformação no ensino, mediante atuação revolucionária e sistema de administração republicano. A PW foi a aplicação e a comprovação prática dos fundamentos da Antroposofia (STEINER, 2018a).

De acordo com a FEWB, a PW está integrada à configuração oficial do ciclo básico da educação em nosso país, conforme as diretrizes legais ${ }^{6}$. Ademais, uma escola Waldorf tem como propósito formar indivíduos em condições de zelar por sua liberdade e responsabilidade por suas decisões, a fim de garantir o seu bem-estar e a sua contribuição para o mundo. Para tanto, considera-se a faixa etária e a individualidade da criança, a fim de que possa reconhecer dentro de si as experiências para as quais está pronta para viver. (FEWB, 2020).

É importante considerar a visão Antroposófica do ser humano para a qual os aspectos anímicos e espirituais se desenvolvem de maneira mais pronunciada, dependendo de cada fase. Nesse sentido, denominou de setênio as etapas de aproximadamente sete anos que o ser humano vivencia durante toda a vida, desde o nascimento. Nessa perspectiva, a pessoa apresenta uma composição quaternária, ou seja, dispõe de 4 membros (corpo físico, corpo etérico, corpo astral e o "eu") que vão amadurecendo no decorrer da vida em processos, em graus de conscientização. Quanto às atividades anímicas do ser, encontra-se a área do pensar, sentir e querer, aspectos básicos para a organização das disciplinas e apresentação dos conteúdos (LANZ, 2019).

\footnotetext{
${ }^{6}$ As escolas Waldorf filiadas à FEWB são organizações associativas de direito civil que possuem uma entidade mantenedora sem fins lucrativos. São instituições auto administradas, cuja forma de trabalho é comunitária. A gestão é responsabilidade compartilhada por professores e pais, os quais proveem os recursos necessários ao seu funcionamento. Nos estados do RJ, MG, BA, SE, PB, SP e no DF há iniciativas de escolas públicas que adotam a PW. Elas são escolas mantidas por associações ou custeadas pelos munícipios. Disponível em: https://institutoruthsalles.com.br/capitulo-i-introducao-e-legislacao/.
} 
Nessa concepção, o caminho para a aprendizagem na PW se faz por meio do processo pelo qual a informação é elaborada intelectualmente (pensar), passa pelos órgãos dos sentidos (sentir) e, mediante a vontade, determina um agir, transformando-a em conhecimento. O que é captado intelectualmente tem sustentação em sentimentos e emoções que acompanham a experiência. Essa integração é viabilizada pela expressão artística que permeia todas as áreas do conhecimento (FEWB, 2020).

Vale observar que o currículo e as práticas pedagógicas na PW apresentam algumas singularidades ${ }^{7}$. Segundo Paula e Moreira (2021, p. 10), o currículo na PW, "além das matérias básicas, oferece especial atenção para o ensino das artes, manualidades, movimento e educação ambiental. Entretanto, o fazer artístico não se limita às disciplinas específicas, ele deve estar presente na prática pedagógica de todos os professores". Carlgren e Klingborg (2014) mencionam ainda o ritmo diário, a aula em épocas e a palavra falada. Como nas escolas Waldorf não se adota material apostilado, os conteúdos são apresentados oralmente e estes são registrados pelos alunos em seus cadernos em forma de textos e ilustrações.

Fundamentado nos pressupostos teóricos de Rudolf Steiner, Lievegoed (2017) distingue, sob o ponto de vista biológico, três grandes períodos de aproximadamente 7 anos no desenvolvimento de crianças e jovens: o primeiro entre o nascimento até a troca dos dentes; o segundo, entre a troca dos dentes e a puberdade; e o terceiro entre a puberdade e a maioridade. Segundo essa ótica, no segundo setênio (entre 7 e 14 anos) ocorre uma evolução psicológica na qual o pensar, o sentir e o querer passam a evoluir no âmbito da personalidade. Conforme revelou Lanz (2019), nesse setênio acontece o amadurecimento do corpo astral e da individualidade sentimental. Nessa fase, os sentimentos e as emoções se evidenciam na personalidade das crianças, além de que uma quantidade maior de conhecimentos já pode ser assimilada por meio da memória que se desenvolve.

Steiner aborda a questão de o jovem alcançar a segurança interior necessária à vida, advindos da experiência de ser e se sentir competente, proporcionada pela permeação do corpo físico, pelo espírito e pela alma, conforme proposições da Antroposofia. Essa é uma das metas ao direcionar as atividades ou matérias de determinadas maneiras, em certas épocas. A PW faz

\footnotetext{
7 Além dos componentes curriculares preconizados pela BNCC, o currículo da PW acrescenta matérias denominadas de complementares ou parte diversificada, tais como: desenho de formas; música; artes plásticas (pintura em aquarela, modelagem, escultura em argila; desenho em preto e branco e em perspectiva); artes cênicas (euritmia, arte da fala e teatro); artes aplicadas (marcenaria); trabalhos manuais (tricô, crochê, bordado e costura); segunda língua estrangeira (espanhol) e horticultura/jardinagem. Disponível em: http://www.fewb.org.br/imagens/secao/documentos/3\%20Caracteristicas\%20Essenciais\%20da\%20Pedagogia\%2 oWaldorf.pdf. Acesso em 04 set. 2020.
} 
a transição para um encaminhamento realmente prático no ensino e na educação que precisavam ser encontrados, para que "todo o direcionamento da educação seja voltado para a vida prática" (STEINER, 2013, p. 137). Entre as ações com forte cunho pedagógico, estão as excursões, viagens de campo e o teatro que são acontecimentos incisivos na opinião de Steiner, cujo valor pedagógico é evidente (LANZ, 2019).

Valendo-se das concepções de Steiner, Lanz (2019, p. 50-51) confirma que "[...] o sentimento do belo deve ser cultivado por meio de atividades artísticas e artesanais, isto é, por meio do 'fazer'. A relativa passividade do aprender será, dessa forma, completada por uma atividade criativa". Nessa atmosfera, o exercício da vontade é praticado por todo o currículo Waldorf por meio de atividades que exigem repetição. Entre a audácia e a paciência, ocorre a formação de uma imagem e a vivência do envolvimento de toda personalidade. Assim, pintar, modelar, fazer música, recitar, representar e costurar não têm o intuito de formar especialistas, mas de proporcionar uma experiência múltipla que requer persistência, perseverança e solidariedade para que possam, também, no futuro, enfrentar a formação unilateral (CARLGREN; KLINGBORD, 2014).

Steiner desenvolveu uma teoria do conhecimento a qual "[...] identifica um caminho que conduz a atividade cognitiva humana para além do pensamento meramente representativo e intelectual, em direção a um pensar vivo - ou dinâmico" (STEINER, 2018b, p. 12). Valendose da cosmovisão de Goethe, Steiner vê, em cada ser humano, a capacidade inata de um pensar intuitivo que é resultante do encontro entre impressões sensoriais, recebidas de fora com as intuições ativas de seu interior, resultando em um conceito de realidade diferente daqueles cujos processos são estáticos, acabados e fora da consciência do ser humano. Logo, trata-se de uma forma ampliada de conhecer e pensar o mundo e a si próprio. Todavia, essa visão normalmente não é ensejada pela maioria dos sistemas educacionais tradicionais (STEINER, 2018b).

Steiner (2016) aborda questões pedagógicas e didático-metodológicas ${ }^{8}$, entre outros aspectos, trata da importância de o professor acompanhar os estudantes o maior tempo possível. Dessa forma, o professor e a classe, ao longo de oito anos, tempo aproximado que o professor de classe permanece com a mesma turma, formam uma comunidade. Steiner enaltece a função do professor nesse processo: “[...] tão importante quanto a discussão sobre o que a criança deve aprender, e se ela deve ser educada de forma intelectualista ou de acordo com sua natureza

\footnotetext{
${ }^{8} \mathrm{Na}$ ocasião da fundação da Escola Waldorf Livre, no ano de 1919 em Stuttgart, Steiner proferiu catorze palestras sobre debates pedagógicos e metodológico-didáticos. As palestras foram traduzidas, organizadas e publicadas em 3 livros: "A arte da Educação" volumes I, II e III.
} 
volitiva, para a pedagogia também é importante decidir a questão: como o professor deve atuar? (STEINER, 2014, p. 198).

Estudos realizados por Martins e Romanelli (2018) contribuem com as reflexões sobre a atuação do professor. Ao discorrerem a respeito das concepções de Freire e de Steiner, as autoras constataram que, na PW,

[...] é grande a responsabilidade do educador, pois, o aluno aprende de pessoas e de vivências. Por isso, o professor necessita de estar sempre estudando e aprofundandose no conhecimento do Ser Humano e do Universo em suas diferentes categorias. Desse modo, fica claro que ensinar não é apenas transferir conhecimento, e sim criar alternativas e possibilidades para a sua construção. Cabe ao educador tornar seu aluno um ser ativo e participante durante as atividades (MARTINS; ROMANELLI, 2018, p. 349).

Compreendidos os princípios e fundamentos da prática pedagógica da educação Waldorf bem como a importância do professor no processo de ensino e aprendizagens, tornase relevante apresentar estudos já realizados com egressos dessa pedagogia. Assim, na próxima subseção, são apresentados resultados de algumas pesquisas que contribuíram para a análise e discussão dos dados.

\subsection{Pesquisas com/sobre os egressos da Pedagogia Waldorf}

Universidades e institutos alemães e norte-americanos realizaram pesquisas científicas com intuito de avaliar a formação dos egressos da PW, além de outros trabalhos que foram desenvolvidas em países, como Canadá, Suíça, Suécia e Dinamarca ${ }^{9}$. Sobre a realidade brasileira, Bach Júnior (2016) ${ }^{10}$ aponta para a carência de estudos sobre a temática. Em sua maioria, os estudos com egressos da PW ocorreram com o intuito de entender como os egressos avaliavam a repercussão da educação Waldorf em suas vidas pessoais, acadêmicas e profissionais, a fim de desvelar alguns mitos do senso comum e equívocos sobre a formação, além de indicar pontos fortes e possibilidades de mudanças.

Essas pesquisas foram direcionadas, predominantemente, a jovens e adultos egressos da PW que já haviam concluído o EM, estavam cursando ou já tinham terminado o curso superior e/ou atuavam no mercado de trabalho. Os principais aspectos investigados se referiam ao perfil

\footnotetext{
${ }^{9}$ A ECSWE.EU (Conselho Europeu para Educação Waldorf Steiner) é uma organização que representa escolas de 28 países da educação Waldorf na Europa. A WREN (Waldorf Research Education Network) é uma rede vinculada ao Conselho Europeu que compartilha pesquisas sobre a educação Waldorf. Localizou-se no site da WREN 8 pesquisas sobre a formação dos egressos Waldorf desenvolvidas na Alemanha, Estados Unidos, Suécia, Suíça, Dinamarca e Brasil entre 2003 e 2007.

${ }^{10}$ Bach Júnior (2016) no livro "Como vivem os alunos Waldorf” tematiza a vida dos egressos da PW, embasado em parâmetros concretos de avalição, oriundos de pesquisas empíricas.
} 
dos egressos quanto ao desempenho no vestibular e percurso acadêmico (GERWIN; MITCHELL, 2007; PACÍFICO; MARCONDES, 2016; PILONI, 2008); escolha e satisfação profissional (BACH JÚNIOR, 2016; BARZ; RANDOLL, 2007; GERWIN; MITCHELL, 2007; PILONI, 2008); impacto na vida profissional (PACÍFICO; MARCONDES, 2016) inserção e atuação no mercado de trabalho (BACH JÚNIOR, 2016); habilidade para lidar com situações competitivas (PACÍFICO; MARCONDES, 2016); impacto na vida pessoal e/ou social (BACH JÚNIOR, 2016; BARZ; RANDOLL, 2007; GERWIN; MITCHELL, 2007; PACÍFICO; MARCONDES, 2016); influências religiosas (BACH JÚNIOR, 2016; BARZ; RANDOLL, 2007; RIBEIRO; PEREIRA, 2007); e, contato com a cultura midiática (BACH JÚNIOR, 2016).

De acordo com os resultados dessas pesquisas, os egressos da PW avaliam positivamente a formação recebida. Quanto aos aspectos levantados, os referidos estudos revelaram que: a) a maioria foi aprovada em exames vestibulares (GERWIN; MITCHELL, 2007; PACÍFICO; MARCONDES, 2016; RIBEIRO; PEREIRA, 2007) em faculdades expressivas (RIBEIRO; PEREIRA, 2007) e cursaram carreira variadas (PACÍFICO; MARCONDES, 2016); b) estavam no mercado de trabalho, sentiam-se aptos a vivenciar situações competitivas (PACÍFICO; MARCONDES, 2016; RIBEIRO; PEREIRA, 2007) e poucos seguiram carreira artística (RIBEIRO; PEREIRA, 2007) e, c) não constataram doutrinação religiosa (PACÍFICO; MARCONDES, 2016; RIBEIRO; PEREIRA, 2007; SETZER, 2017).

Por outro lado, mencionaram a reformulação curricular como um dos pontos que poderia ser melhorado (BACH JÚNIOR; GUERRA, 2018; BARZ; RANDOLL, 2007). No estudo de Barz e Randoll (2007), os egressos de escolas suíças e alemãs indicam as áreas de ciências e línguas estrangeiras como as que devem ser reformuladas e acrescentam também a necessidade de promover a qualificação dos docentes, a fim de atender às demandas da sociedade. Corroboram Bach Júnior e Guerra (2018) ao abordar a tensão entre idealidade e realidade da aplicação de princípios curriculares, o conflito entre posturas progressistas e conservadoras e a necessidade de atualização do currículo Waldorf em uma perspectiva histórico-cultural.

Sob outra óptica, a pesquisa realizada por Gerwin e Mitchell (2007) com egressos de escolas secundárias Waldorf canadenses e estadunidenses apontou que os estudantes compartilham três principais características: valorizam a oportunidade de pensar por si e de colocar suas ideias em prática, apreciam a durabilidade dos relacionamentos e buscam 
oportunidade para ajudar os outros, se julgam guiados por elevados princípios éticos e valores morais que auxiliam na superação de desafios profissionais e privados.

Essas pesquisas também anunciaram que as artes foram valorizadas pelos depoentes para a formação humanística, para o conhecimento e que, durante o período da vida acadêmica (PILONI, 2008), a formação humanística, característica da PW, é a principal razão da procura pela escola Waldorf (AZEVEDO; OLIVEIRA, 2018); que os egressos têm sentido de estética altamente desenvolvido (GERWIN; MITCHELL, 2007); os egressos se tornaram leitores ativos (PACÍFICO; MARCONDES, 2016), além de contribuir para o aprendizado de viver, do respeito ao próximo, da aceitação das diferenças e da solidariedade (PILONI, 2008).

É interessante notar que a maioria dos estudos se refere a egressos que concluíram o EM. E se por um lado esses estudos avaliam um ciclo mais completo, por outro, não são condizentes com a nossa realidade, visto o reduzido número de estabelecimentos desse nível de escolarização (FEWB, 2020; RIBEIRO; PEREIRA, 2007). Vale observar que, por se direcionar ao grupo constituído, predominantemente, de jovens e adultos, as pesquisas orbitam em torno de questões do âmbito profissional.

Considerando que o número de alunos do EF é maior que do EM, compreendemos ser pertinente identificar a percepção desses egressos sobre a formação recebida e avultamos o fato de as impressões estarem mais vívidas. A partir desse ponto, descreveremos o percurso metodológico adotado no processo de coleta, organização e tratamento dos dados empíricos.

\section{Procedimentos do MÉtodo}

Esta pesquisa qualitativa do tipo descritiva envolveu um grupo que apresenta características específicas, no qual foi possível relacionar variáveis, levantar opiniões ou crenças. Para a coleta de dados, optou-se pelo questionário escrito e autoaplicado com perguntas abertas, porque esse instrumento possibilita mais liberdade de expressão para os depoentes (GIL, 2012). Esse instrumento foi composto por questões visando identificar dados sobre a escolarização, a formação na Educação Waldorf e o processo de transição.

Para Lüdke e André (2017), a construção de um conjunto de categorias descritivas é o primeiro passo para a fase formal de análise dos dados. Neste estudo, primeiramente retornouse ao objetivo da pesquisa, posto que, a partir das inquietações de um problema, se desenvolve uma investigação. Essa atitude orientou o processo interpretativo no que tange a temas, a aspectos, a dados, a elementos, a fatos, a conteúdos e a saberes que poderiam ser mencionados pelos egressos sobre a formação recebida. 
À luz do aporte teórico, emergiam, a princípio, categorias relacionadas às contribuições da PW pertinentes à formação integral do educando, às singularidades curriculares e metodológicas, à atenção especial à arte e ao convívio social. Nesse sentido, leituras sucessivas das respostas dos egressos resultaram em um conjunto inicial de termos, palavras, expressões e frases que se destacaram, porque dialogavam com o escopo da pesquisa. A partir dos dados empíricos, sobressaíram também elementos concernentes à importância do professor, aos processos avaliativos e à proposição da adequação da PW ao nível do EF. Os destaques das respostas dos egressos, assim que foram anotados, constituíram uma lista de sentidos. Posteriormente, esses sentidos foram reexaminados e reunidos em temas, conforme a articulação entre a revisão de literatura e os apontamentos dos egressos, formando unidades de significados (MINAYO, 2011).

Desse modo, ancorados no referencial teórico e nas respostas dos egressos, estabeleceram-se os seguintes temas: 1. O caminho da aprendizagem na percepção dos egressos; 2. Processos avaliativos e percepção de adequação para o nível do EF; e, 3. O papel do professor, as relações sociais e a formação mais humanizada. Nos depoimentos relacionados aos temas, as falas selecionadas foram transcritas na íntegra, sem receber correções ortográficas.

Cuidados éticos e metodológicos são fundamentais em pesquisas qualitativas. Nesse sentido, informou-se aos participantes sobre a pesquisa, assegurou-se o seu anonimato e o sigilo das informações (LÜDKE; ANDRÉ, 2017). O primeiro contato ocorreu com os pais por meio de Carta de Apresentação em que assinaram o Termo de Consentimento Livre e Esclarecido, autorizando a participação dos filhos na pesquisa. Posteriormente, os egressos foram contactados individualmente e, após serem esclarecidos sobre a pesquisa, assinaram o Termo de Assentimento e levaram o questionário para responder em horário e local de suas preferências.

A coleta de dados empíricos ocorreu entre os anos de 2019 e 2020. Os 17 primeiros egressos identificados no estudo responderam ao questionário em junho de 2019 e, entre dezembro de 2019 e março de 2020, ampliou-se a amostra para mais 11 egressos. No total, participaram da pesquisa 28 jovens com idade entre 14 e 18 anos, média de idade de 16 anos, 17 do sexo feminino e 11 do sexo masculino, sendo que todos os partícipes são provenientes de 
2 escolas privadas de Cuiabá-MT as quais adotam a metodologia Waldorf ${ }^{11}$. Considera-se a amostra representativa, visto que essas eram as únicas escolas Waldorf no Estado de Mato Grosso que ofertavam o EF completo.

Entre os participantes, 20 ingressaram em escola de metodologia Waldorf com idade entre 1 e 4 anos; 22 estudantes tinham entre 9 e 13 anos de escolarização Waldorf; 22 participantes estudaram o nível Fundamental na escola federada. Dentre estes, 13 terminaram o $8^{\circ}$ ano em 2016, 8 concluíram o $9^{\circ}$ ano em 2019 e 1 concluiu em 2014. Vale destacar que 6 egressos estudaram na escola Waldorf não federada, sendo 5 até o $1^{\circ}$ ano do $\operatorname{EM~}\left(10^{\circ}\right.$ ano Waldorf) e 1 até o $8^{\circ}$ ano. Os participantes continuaram os estudos no EM em instituições não Waldorf, sendo 2 em escola Federal de EM, 1 em escola confessional e os demais 25 em 2 escolas particulares. Dos participantes da pesquisa, 25 egressos estudavam em Cuiabá, 2 em outros estados e 1 em uma escola na Suíça.

Vale observar que o convite decorreu da facilidade de acesso aos egressos e que o anonimato foi mantido durante todo o processo. Para a apresentação e discussão dos resultados, os partícipes foram distinguidos por letras e números usados para identificar sexo, idade e tempo de escolarização na PW. Assim, a letra E se refere a egresso; os números identificam o participante (de 1 a 28); F para feminino e M para masculino; a idade é seguida da letra A, e EW refere-se ao tempo de escolarização Waldorf, conforme exemplo: (E13M, 16A, 12EW). Descrito o percurso metodológico, encaminhamos para a apresentação e discussão dos dados.

\section{APRESENTAÇÃO E DISCUSSÃO DOS RESULTADOS}

Com propósito de identificar a percepção dos egressos do Ensino Fundamental quanto aos processos formativos oriundos da PW, perguntou-se a 28 estudantes como eles analisavam a preparação/educação recebida na escola Waldorf. De acordo com os dados empíricos, 27 participantes avaliaram que se sentiram bem preparados com a educação Waldorf. Dos egressos pesquisados, somente um egresso avaliou negativamente.

$\mathrm{Na}$ análise do conteúdo das falas, foi possível identificar que os estudantes valorizaram as práticas e as relações educativas fomentadas na PW, entretanto, 10 depoentes fizeram ponderações quanto aos processos avaliativos, destacando a necessidade de aprofundamento nas disciplinas da área de Ciências e a percepção de se adequar a metodologia para o nível do

\footnotetext{
${ }^{11}$ Atualmente, no estado de Mato Grosso há 9 escolas Waldorf: 2 filadas, 3 em processo de filiação e 4 não filiadas. Disponível em: http://www.fewb.org.br/encontre escola.html. Acesso em 04 set. 2020.
} 
EF. Além disso, 16 abordaram a formação humana, mencionando que a preparação recebida em todas as áreas será relevante para a vida.

Ao estabelecer diálogo entre os dados e o referencial teórico, emergiram 3 categorias que versam sobre os processos didático-metodológicos, a dimensão social e o processo avaliativo.

\subsection{O CAMINHO DA APRENDIZAGEM NA PERCEPÇÃO DOS EGRESSOS}

Nesta subdivisão, será apresentada a percepção dos participantes da pesquisa sobre o modo de como se aprende na PW. Em suas respostas, destacaram a relevância da organização do ensino, os componentes curriculares e as vivências. Nesse sentido, os depoimentos trazem afirmações de que os estudantes desenvolveram habilidades para pensar mediante vivências, as quais facilitaram a aprendizagem. $\mathrm{O}$ ensino em épocas, as aulas práticas, as experiências, as dinâmicas e as disciplinas complementares também foram recorrentes nas declarações.

Sobre a formação recebida para o domínio do pensar, trazemos o recorte da fala de três estudantes: o primeiro destacou a "[...] habilidade de pensar e compreender bem rapidamente, já que nos primeiros anos escolares, vemos e praticamos detalhadamente as teorias e conceitos das matérias. Raciocínio lógico que eu não identifiquei por parte dos outros alunos não Waldorf” (E1F, 16A, 10EW); o segundo e “[...] a maneira com que a criatividade e a imaginação do indivíduo são estimuladas, tornando mais fácil os raciocínios abstratos e lógico, que contribuem muito com o desenvolvimento do estudante" (E17M, 16A, 9EW) e o terceiro frisou que "[...] a escola Waldorf me ensinou a pensar, a entender o porquê das coisas. E esse pensar nos leva a compreender o que torna o aprendizado natural" (E28F, 15A, 13EW). Depoimentos de outros 7 egressos também sinalizaram o aprimoramento do pensar, permeado pelo sentir e pelo querer.

De acordo com a FEWB (2020), a PW desenvolve o pensar de forma adequada a cada faixa etária em sintoniza com sentimentos equilibrados que fomentam a força de vontade e determinação. Paula e Moreira (2021) reforçam que aspectos básicos para a organização dos componentes curriculares e para a apresentação dos conteúdos são a presença e proporção dos elementos pensar, sentir e querer, de acordo com a faixa etária. Considerando que a proporção difere entre as idades, o pensar vai se tornando mais conceitual, conforme o avanço dos setênios, como uma participante afirmou: “[...] avalio que os conteúdos, do ensino fundamental - foi o que estudei no Waldorf - foram de acordo com a idade [...] tem muitos conteúdos que só fazem sentido com mais maturidade das crianças" (E18F, 18A, 9EW). 
As vivências e as dinâmicas que permeiam todo o ensino Waldorf foram apontadas por 15 egressos como contribuições para a formação de uma base sólida de aprendizagem, como ilustram as seguintes falas: "A pedagogia Waldorf me deu uma base muito sólida. O conteúdo aprendido na escola Waldorf foi fortemente internalizado através das atividades práticas e teóricas" (E28F, 15A, 13EW); "O fato de ter bastante aulas práticas facilitava o processo pois aprendemos na teoria e na prática [...]" (E27M,15A, 6EW). No tocante ao método em si, os egressos enfatizaram os processos, os quais entrelaçam teoria, prática e o ensino em épocas.

Segundo PILONI (2008, p. 39), esse tipo de ensino, "Levando os alunos a vivenciar intensamente cada matéria, [...] favorece um maior aprofundamento dos assuntos, na medida em que lhes possibilita receber os conteúdos de forma não fragmentada". A respeito do ensino em época, três participantes afirmam que “[...] o modelo de aula sendo por 'épocas' é muito bom para que se possa realmente aprender e vivenciar um conteúdo por vez, sendo que assim a gente pode realmente entender e também aprender mais" (E18F, 18A, 9EW); “[...] a escola Waldorf tem um ótimo ensino, especialmente por focarem cada mês em uma matéria, assim, não deixa o aluno esquecer o conteúdo quando vai aprender sobre outros assuntos da mesma matéria" (E5F, 16A, 11EW); "Eu senti um baque muito grande quando saí da pedagogia Waldorf e entrei na tradicional. A maneira utilizada, principalmente as épocas, facilitam demais no aprendizado" (E26F,14A, 6EW).

Para Carlgren e Klingborg (2014), o ensino em épocas forma uma unidade de ensino com duração média de 4 semanas, possibilitando grande força de concentração. Essa estratégia atua de maneira benéfica e disciplinadora, concentra e ativa o interesse em uma época na qual as pessoas estão muito estimuladas, e as crianças e jovens estão sujeitas a muitas distrações. Notamos que, para os participantes, esse procedimento facilitou a aprendizagem e contribuiu para a sua formação.

A maioria dos participantes da pesquisa também avaliaram as matérias complementares (artes e manualidades) como importantes componentes do currículo para a formação geral do estudante, conforme as seguintes respostas de dois jovens: "Outra característica boa da escola Waldorf é o ensino em matérias diferentes como, por exemplo, ética, trabalhos manuais, música, artes, jardinagem e teatro, [...] o que eu considero muito importante para a grade curricular do aluno" (E7M, 16A, 5EW). Para o participante número 8, “[...] os pontos fortes são as aulas não tradicionais, como música, trabalhos manuais e artes, que podem não ser voltados para vestibular, mas para a vida" (E8M, 16A, 11EW). 
Nota-se que os egressos têm visão abrangente sobre formação escolar bem como valorizam as habilidades e competências que a PW lhes proporcionou, como destaca outra estudante em sua fala:

Estudar a maior parte da vida nessa pedagogia prepara o indivíduo indiretamente para a vida adulta e desenvolve a criatividade, habilidade de comunicação, aflora o amor pela arte (produzir ou admirar), pela música, desenvolve melhores habilidades manuais que são utilizadas em diversas áreas do conhecimento, além da empatia e o bom caráter valorizados e ensinados pela escola (E4F, 16A, 12EW).

$\mathrm{Na}$ atmosfera da Escola Waldorf, o ensino vivo é impregnado, permeado pelo elemento artístico, conforme notou Steiner (2018a, p. 18): "E dessa didática viva só pode emanar aquilo que deve penetrar no coração, na índole e no intelecto da criança". Paula e Moreira (2021) reafirmaram que, na prática pedagógica de todos os professores, o fazer artístico deve estar presente. Logo, o professor exerce um papel primordial na PW. A esse respeito, os participantes falaram da importância da relação professor-aluno para o aprendizado. A dimensão social será contemplada na terceira categoria.

\subsection{Processos aValiativos e a PerCePÇÃo de ADEQUaÇão Para O NíVEL do EF}

Entre os 27 egressos que avaliaram positivamente a formação recebida na escola Waldorf, 10 apontaram que a PW seria apropriada para o nível do EF e que necessitaria de aprofundamento nas áreas de Física, Química e Biologia, além de uma melhor preparação dos estudantes para a realização de testes e provas, como se pode conferir na fala a seguir: "[...] com a ausência de muitas provas [...] acredito que a preparação da escola Waldorf seja um pouco precária em alguns pontos na formação do estudante vestibulando. Além disso, não tinha costume de fazer provas toda semana, então ficava muito nervosa" (E19F, 17A, 13EW). A participante de número 5 afirma que o ensino é ótimo, “[...] Porém, não foca muito em aprovações em testes, faculdades, Enem, entre outros, deixando o aluno desinformado sobre isso, assim, podendo causar um prejuízo futuro" (E5F, 16A, 11EW). Outro egresso complementa: “[...] falta de testes avaliativos que podem levar à reprovação ou dependência em escolas tradicionais. Percebi que avalições formais quando bem elaboradas e se o conteúdo é bem ensinado, desafiam e estimulam o aluno a estudar mais em várias ocasiões” (E17M, 16A, 9EW).

O egresso de número 14 apontou a questão da formação na área de Ciências ao afirmar que a PW “[...] forneceu uma excelente base para que pudesse ter bom desempenho na mudança para a escola não Waldorf. Talvez um único ponto a melhorar seria [...] nas áreas de Física, 
Química e Biologia” (E14M, 16A, 12EW). Outro participante reforçou: “[...] na questão de conteúdos como Biologia, Física e Química, tivemos muitas experiências práticas, mas pouca teoria [...]" (E8M, 16A, 11EW). Embora os egressos tenham valorizado as atividades práticas e a formação recebida, apontaram a quase ausência de provas e a pouca teorização na área das ciências como aspectos a serem revistos. Apesar de as áreas mencionadas adquirirem especificidade no EM, depoimentos do grupo pesquisado aventam que o EF carece de aprofundamento teórico nessas subáreas.

Em algumas respostas fica evidente que determinados estudantes já apresentavam o desejo de trocar de escola em decorrência das demandas do EM: "Acredito que a educação fundamental é incrível e muito completa, mas a do ensino médio deixa e desejar [...]" (E9F, 16A, 9EW), ou ainda: “Até o ensino fundamental acho uma formação boa, porém no ensino médio a escola Waldorf não dá vontade de ficar revisando os conteúdos, pois é fácil passar de ano e por isso não dá nenhum estímulo para estudar" (E13M, 16A, 12EW). Steiner (2013) afirma que, aos 14 anos, os estudantes já estariam preparados para serem transferidos para outra escola, caso quisessem, e esse pareceu ser o desejo de alguns deles.

Sob outra perspectiva, uma egressa respondeu, que ao ingressar em uma escola tradicional, foi necessário somente uma revisão dos conteúdos: “A educação que eu recebi na escola Waldorf foi boa, algumas falhas em alguns pontos, porém, aprendi todos os conteúdos, só precisei fazer uma revisão quando saí da [nome da escola Waldorf]” (E15F, 16A, 12EW). Outra participante pontuou: "Tudo que recebi na escola Waldorf para minha formação sempre foi muito útil, não me senti atrasada vendo os outros estudantes" (E2F, 16A, 13EW).

Lanz (2019, p. 117) afirma que "o currículo Waldorf tem se mostrado mais amplo e mais rico do que os currículos oficiais, cujas exigências mínimas são sempre satisfeitas, embora, às vezes, com defasagem quanto à época em que são cumpridas”. Acerca dessa possível defasagem, uma das egressas pesquisadas fez a seguinte constatação: “Quando mudei de escola, percebi que algumas coisas que estavam aprendendo eu já havia estudado, e outras que não havia estudado, mas meus colegas já sabiam. Então, acho que a sincronização da matéria de uma escola para outra não é fiel” (E10F, 14A, 9EW).

Bach Júnior e Guerra (2018) discorreram sobre o currículo Waldorf, contemporizando as necessidades pertinentes ao EM ao evidenciar que o currículo assumiu um aumento de conteúdo no mesmo período de tempo. Os autores destacam, ainda, o debate acerca do ensino qualitativo de Ciências na EW, o qual se dá com propósito humanizante. Nesse sentido, 
reforçam a necessidade de se refletir sobre as condições atuais de ensino e a coerência curricular, e esse pareceu ser o anseio de parte do grupo pesquisado.

Sobre a preparação para provas, exames e vestibulares, Steiner (2013) afirma que, na educação Waldorf, o parâmetro diz respeito ao que a criança e o jovem necessitam e precisam saber em determinada idade, e não o que eles já são capazes. Todavia, vale ressaltar que já se passou um século desde a primeira escola Waldorf, e que as demandas acadêmicas atuais são outras. Nesse sentido, há uma inevitável tensão nessa polarização quando estamos diante de metodologias díspares em seus preceitos teóricos, didáticos e metodológicos.

Em contraponto a essa afirmação de Steiner, o estudante de número 6 foi deveras contundente e tocou em pontos cruciais da educação Waldorf. Vejamos:

\begin{abstract}
A educação Waldorf, para mim, é ultrapassada e deixa de usar equipamentos tecnológicos e mantém o aluno preso a um mundo antigo, separado de toda a realidade contemporânea. Ainda mais, a educação é fortemente ideológica, muito ligada à religião cristã e, por muitas vezes, a educação relembra uma doutrina. Ao invés de deixar o aluno livre para escolher e pensar criticamente sobre o mundo, a escola retira esse pensamento crítico (E6M, 16A, $12 \mathrm{EW}$ ).
\end{abstract}

É possível perceber, nas palavras desse egresso, a sua capacidade crítica e força do "eu" se expressando e se posicionando, conforme o que se espera de um jovem no início do terceiro setênio. Seguramente, faz-se necessário averiguar mais especificamente os elementos por ele apresentados e mencionado por outra depoente: “[...] muitas vezes, a pedagogia fica muito centrada nos valores primordiais e tradicionais, como a não utilização de aparelhos eletrônicos [...]. O equilíbrio entre a tradição e a modernidade seria o ideal” (E1F, 16A, 10EW).

A esse respeito, Bach Júnior e Guerra (2018, p. 864) asseveram que “[...] O desafio da compreensão dos aspectos intrínsecos ao currículo inclui a relação tensa entre o que foi idealizado e a dimensão histórico-cultural, permeada de transformações ao longo do tempo". Sobre os propósitos educacionais para os jovens, os autores preconizam:

No Ensino Médio, a cada geração há uma adolescência que, no afã de conquistar sua autonomia adulta, já possui uma articulação com o mundo independentemente da família e da escola, e, por apresentar questionamentos e necessidades condizentes com sua condição temporal, coloca o desafio aos educadores de uma atualização dos propósitos educativos (BACH JÚNIOR; GUERRA, 2018, p. 871).

Bach Júnior e Guerra (2018) também mencionam a inserção do ensino de computação e tecnologias e o desenvolvimento de métodos específicos para o EM, notadamente devido ao aumento do volume de conhecimento dos últimos anos e ás inevitáveis competições por meio de provas e testes para ingresso em universidades. Segundo esses autores, as revisões 
curriculares para o EM são, consequentemente, necessárias, corroborando com a pesquisa de Braz e Randoll (2007).

Sobre a opção religiosa e crenças pessoais que também foram mencionadas pelos egressos pesquisados, Bach Júnior (2016, p. 38) verificou em um estudo alemão que "[...] as escolas Waldorf possuem grande abertura às diferentes formas de expressões religiosas do mundo e, também, que os ex-alunos não possuem uma tendência à institucionalização religiosa". A pesquisa concluiu que, além das escolas Waldorf possuírem essa abertura, os egressos também não sofreram pressão para aceitar a imagem antroposófica de ser humano, semelhante ao resultado de outros estudos a esse respeito (PACÍFICO; MARCONDES, 2016; RIBEIRO; PEREIRA, 2007; SETZER, 2017).

\subsection{O PAPEL DO PROFESSOR, AS RELAÇÕES SOCIAIS E A FORMAÇÃO MAIS HUMANIZADA}

Na percepção dos EEF Waldorf, os professores foram fundamentais em suas formações, notadamente por se interessarem pelo aprendizado, pela disponibilidade e interesse para com os estudantes e por conhecerem bem cada aluno, como apontam as falas a seguir: "[...] você realmente aprende, não é como nas outras escolas que eles jogam o conteúdo e você tem que se virar, eles se importam se você está conseguindo entender [...] eles te procuram para ajudar" (E25F,15A, 13EW); "Um ponto positivo na formação é a união e o amor pelos meus colegas e pelos professores. Temos um laço e uma energia impressionante, e eu só tenho a agradecer" (E2F, 16A, 13EW). Segundo outra egressa,

\footnotetext{
No Waldorf, a impressão é de que os professores realmente se importam com o aprendizado dos alunos, não só em passar o conteúdo das provas. [...] a vida dos alunos é muito mais relevante. Quando um aluno não está bem, o professor logo nota e pede para falar com os pais. A gente fica mais confortável com os professores e mais disposto a se abrir (E26F,14A, 6EW).
}

Mediante essas respostas, é possível perceber a estreita relação estabelecida entre professores e estudantes proporcionada pela metodologia. Os egressos também atribuíram importância ao fato de o mesmo professor acompanhar os alunos ao longo dos anos: "“[...] na minha visão é mais fácil aprender com um professor que você conhece bem, e na escola Waldorf um professor acompanha uma sala até que esta sala se forme” (E7M, 16A, 5EW).

A esse respeito, Carlgren e Klingborg (2014, p. 85) afirmam: "que os alunos aceitam mais facilmente algo do professor do qual gostam, que de outro que lhes é estranho. Mas também é verdade que não gostam de nenhum professor que não respeite plenamente sua liberdade interior". Nas falas dos egressos, fica evidente que houve um forte vínculo entre 
professor de classe e alunos. Paula e Moreira (2021, p. 12) asseveram que "[...] o professor constrói uma relação de confiança, de autoridade amada e de profundo conhecimento das qualidades, das dificuldades e das personalidades de seus alunos".

Interessante notar a percepção dos egressos sobre as relações sociais e o processo formativo: "Ali dentro tínhamos apoio quase familiar por parte da equipe inteira e relações muito saudáveis entre os colegas. O clima fraternal e, ao mesmo tempo, disciplinador, foi me moldando durante todo o tempo que passei em contato com a pedagogia" (E28F,15A, 13EW).

Uma das egressas expressa o modo como se aprende vinculado à importância do professor e das amizades para a sua formação: “[...] O jeito que eles ensinam é muito diferente, mas é o melhor jeito, você não tem vergonha de perguntar para o professor, sem todo mundo te julgar, você tem uma relação de amizade com os professores e todos na escola" (E23F, 15A, $11 \mathrm{EW})$. Realmente, o ambiente da escola Waldorf é inclusivo e acolhedor, propiciando relações boas e duradouras. Bach Júnior (2016), embasado em sua experiência enquanto pai, professor e pesquisador da $\mathrm{PW}$, afirma que alguns ex-alunos sentiam nostalgia por não poderem mais estudar em uma escola Waldorf e que associavam a lembrança da escola com uma afetividade positiva.

Embora a pergunta fosse sobre a formação como estudante, os egressos também perceberam a preparação para a vida como um todo. Eles relacionaram fundamentos da PW como fatores contribuintes para a formação mais humanizada. Martins e Romanelli (2018, p. 346) asseveram que "[...] podemos afirmar que o currículo Waldorf, ao valorizar a arte, a criatividade e as relações humanas, proporciona às crianças e jovens uma visão ampla das matérias, possibilitando uma aquisição interdisciplinar dos conhecimentos, e preparando-os para o exercício da cidadania".

A esse respeito, recorremos a três falas: “[...] a Waldorf prepara não somente pessoas para o estudo tranquilo, mas também para uma vida tranquila” (E3F, 16A, 10EW); “[...] ela prepara você para os desafios da vida, te ensina a desenvolver características como concentração, determinação, criatividade, tudo isso sem perder a individualidade como ser humano" (E24M, 15A, 13EW). A terceira egressa enfatizou:

Claro que conteúdos mais técnicos para o vestibular eu não aprendi no Ensino Fundamental, mas isso não foi empecilho para eu aprender depois. Acho que a formação mais humana teve mais importância e impacto na minha vida do que só o ensino de conteúdos (E18F, 18A, 9EW).

É perceptível que o modo como os egressos avaliaram a formação recebida passa necessariamente pela valorização das relações sociais e preparação integral. Com respeito ao 
caráter humanístico da formação, trazemos depoimentos de mais 5 egressos: "[...] Acho que a escola Waldorf nos torna mais humanos e mais preparados para o futuro" (E15F, 16A, 12EW); "[...] É um método humanitário, essencial no mundo meio chato e automatizado de hoje" (E8M, 16A, 11EW); “A escola Waldorf te ensina a ser um ser humano mais solidário, hoje em dia existe muito preconceito [...] e a escola Waldorf te ensina a aceitar as diferenças [...]" (E24M, $15 \mathrm{~A}, 13 \mathrm{EW})$; "A ter preocupação com o mundo que eu vivo, com o meio ambiente, com os animais e com as questões sociais" (E18F, 18A, 9EW). Outra participante complementa: “[...] ele não só nos prepara para a carreira profissional, mas também pessoal. Saber como agir, pensar, se virar diante de qualquer situação. É a base do conhecimento e essencial na educação" (E20F, 16A, 8EW).

Semelhante ao último depoimento, outros estudantes também mencionaram que a PW contribuiu para sua formação no sentido de proporcionar saberes relacionadas à resolução de problemas, persistência e superação de obstáculos, como destacam as falas a seguir: "A visão que nos mostram das coisas, são as infinitas possibilidades que nós acabamos percebendo que podem existir” (E22F, 15A, 12EW); “[...] a não desistir frente a um desafio, mas sempre buscar outras formas de resolvê-lo" (E27M, 15A, 6EW); "Me ensinou a entender meus próprios limites, a sempre dar meu melhor e nunca desistir diante de um desafio ou adversidade" (E18F, 18A, 9EW).

Piloni (2008, p. 90) também encontrou menções a esse respeito: "Foram muito frequentes as referências ao aprendizado de viver [...]”. Por conseguinte, concordamos com a proposição de Lanz (2019, p. 172), segundo a qual: “[...] a finalidade de todo ensino é preparar a criança para a vida".

\section{CONSIDERAÇÕES FINAIS}

Com pouco mais de um século de separação entre o surgimento da PW e os dias de hoje, são visíveis as diferenças sociais entre as duas épocas. Porém, se observa que a capacidade de decidir sobre si mesmo e fazer escolhas conscientes continua premente, tanto quanto outrora. A partir dos pressupostos teóricos-didáticos-metodológicos, a PW busca a unidade com o mundo, estabelecida pela estruturação do pensar, sentir e agir humanos.

Os resultados apontam o posicionamento de jovens egressos da PW sobre a formação recebida. A partir das suas respostas, compreendemos que se sentiram bem formados para prosseguirem os estudos em escolas não Waldorf, à medida que afirmaram terem recebido uma formação sólida e consistente, sustentada por bases bem fundamentadas e fortemente 
internalizadas que dão suporte para fazerem afirmações pertinentes ao estágio do EM. Entre os alunos que avaliaram positivamente, observamos, em algumas respostas, que os egressos compreendem que a metodologia é adequada predominantemente para o nível do EF, mas que não se aplicaria tanto para o Ensino Médio. Alguns ainda indicam quais áreas poderiam ser aprofundadas ou em quais tiveram mais dificuldades, além da necessidade de mais avaliações.

Os egressos Waldorf avultaram a figura do professor como mediador no processo de preparação e formação escolar. Esse papel atribuído ao professor ultrapassa as demandas de conteúdo, pois enalteceram a dedicação, atenção, cuidado com a individualidade e responsabilidade com as quais os docentes olharam para cada um. A intersubjetividade professor-aluno, permeada por aspectos históricos, culturais e sociais, ficou explícita na fala dos alunos. Os estudantes se percebem no processo de se tornarem sujeitos e indivíduos atuantes no mundo e veem, na figura do professor de classe, a sustentação para o devir humano no âmbito escolar.

De certo modo, os egressos participantes da pesquisa se sentem preparados como estudantes, mediante um ensino voltado para a vida prática com implicações na habilidade de pensar. Com exceção de 1, todos os demais salientaram aspectos didáticos e metodológicos relativos à PW e mencionaram os conteúdos artísticos, as vivências, as experiências e os componentes curriculares como fundamentais a sua formação.

Para aqueles que ainda fazem restrições quanto ao repertório cultural dos egressos Waldorf, a pesquisa aponta resultados favoráveis, segundo opiniões dos sujeitos investigados. No entanto, alguns questionamentos feitos sobre as ciências da natureza e a avaliação nos instigam a olhar para o EF e EM Waldorf, a fim de compreender a formação no terceiro setênio. Além disso, faz-se necessário ampliar a compreensão da atualização do percurso curricular Waldorf.

\section{REFERÊNCIAS}

AZEVEDO, Laiana Moraes de; OLIVEIRA, Francine Marcondes Castro. Características das escolas Waldorf no Brasil: um estudo exploratório. In: SEMANA DE PEDAGOGIA UEM, 23.; ENCONTRO DE PESQUISA EM EDUCAÇÃ̃O, 11.; SEMINÁRIO DE INTEGRAÇÃ̃O GRADUAÇÃO E PÓS-GRADUAÇÃO, 2., Pedagogia UEM 45 anos: Desafios na formação de professores, 2018, Maringá. Anais [...] Paraná: Universidade Estadual de Maringá, 2018. [12] p. Disponível em: http://www.ppe.uem.br/semanadepedagogia/2018/T01/01.07.pdf. Acesso em: 30 nov. 2020.

BACH JUNIOR, Jonas. Como vivem os alunos Waldorf. Curitiba: Lohengrin, 2016. 
BACH JUNIOR, Jonas; GUERRA, Melanie Gesa Mangels. O currículo da Pedagogia Waldorf e o desafio da sua atualização. Revista e Curriculum, São Paulo, v. 16, n. 3, p. 857878, jul./set. 2018. DOI: https://doi.org/10.23925/1809-3876.2018v16i3p857-878

BARZ, Heiner; RANDOLL, Dirk. Alumni of German and Swiss Waldorf Schools: An Empirical Study on Education and Creative Living. Research Institute for Waldorf Education, Wiesbaden, febr. 2007. Disponível em:

https://www.ecswe.eu/wren/documents/german_study_of_alumni.pdf.Acesso em 03 ago. 2017.

CARLGREN, Frans; KLINGBORG, Arne. Educação para a liberdade: a pedagogia de Rudolf Steiner. Tradução: Edith Kunze e Kurt O. Kunze. 10. ed. rev. São Paulo: Escola Waldorf Rudolf Steiner, 2014.

FEWB. Federação das Escolas Waldorf no Brasil - Fundamentos da Pedagogia Waldorf. Disponível em: http://www.fewb.org.br/pw.html. Acesso em: 05 mar. 2020.

GERWIN, Douglas; MITCHELL, David. Standing out without standing alone: Profile of Waldorf School Graduates. Research Bulletin, Wiesbaden, v. 12, n. 2, p. 8-16, Spring, 2007. Disponível em: https://www.ecswe.eu/wren/documents/standing_out_without.pdf. Acesso em: 03 ago. 2017.

GIL, Antônio Carlos. Métodos e técnicas de pesquisa social. 6. ed. São Paulo: Atlas, 2012.

LANZ, Rudolf. A pedagogia Waldorf: caminho para um ensino mais humano. 12. ed. São Paulo: Antroposófica, 2019.

LANZ, Rudolf. Noções básicas de antroposofia. 7. ed. São Paulo: Antroposófica, 2005.

LIEVEGOED, Bernard. Desvendando o crescimento: as fases evolutivas da infância e da adolescência. Tradução: Rudolf Lanz. 5. ed. São Paulo: Antroposófica, 2017.

LÜDKE, Menga.; ANDRÉ, Marli Elisa Dalmazo Afonso de. Pesquisa em Educação: abordagens qualitativas. 2. ed. Rio de Janeiro: E.P.U., 2017.

MARTINS, Cálita Fernanda de Paula; ROMANELLI, Rosely Aparecida. Educação básica e a prática docente na concepção de Freire e Steiner: fundamentos da LDB e do PPP da escola Livre Porto Cuiabá. Revista Prática Docente, [S. l.], v. 3, n. 1, p. 334-351, 2018. DOI: 10.23926/RPD.2526-2149.2018. v3.n1.p334-351.id154. Disponível em: http://periodicos.cfs.ifmt.edu.br/periodicos/index.php/rpd/article/view/154/74. Acesso em: 22 mar. 2021.

MINAYO, Maria Cecília de Souza. O desafio da pesquisa social. In: DESLANDES, Suely Ferreira; GOMES, Romeu; MINAYO, Maria Cecília de Souza. (org.). Pesquisa social: teoria, método e criatividade. 30. ed. Petrópolis, RJ: Vozes, 2011.

PACÍFICO, Gabriela de Almeida de; MARCONDES, Francine. Egressos da pedagogia Waldorf no Brasil: repercussões da educação idealizada por Rudolf Steiner na vida de alunos. 2016. Trabalho de Conclusão de Curso (Graduação em Pedagogia) - Universidade Estadual de Maringá, Maringá, Paraná, 2016. Disponível em: 
https://docplayer.com.br/79671062-Egressos-da-pedagogia-waldorf-no-brasil-repercussoesda-educacao-idealizada-por-rudolf-steiner-na-vida-de-alunos-resumo.html Acesso em: 03 ago. 2017.

PAULA, Helena Maria Rodrigues de; MOREIRA, Evando Carlos. A concepção de educação e escola de William Kilpatrick e Rudolf Steiner e suas contribuições para a educação contemporânea. Revista Prática Docente, v. 6, n. 1, e008, 2021, Disponível em: https://doi.org/https://doi.org/10.23926/RPD.2021.v6.n1.e008.id960. Acesso em: 22 mar. 2021.

PILONI, Pedro Roberto. A contribuição da Pedagogia Waldorf na formação de jovens para os desafios do século XXI: A experiência da Escola Livre Porto Cuiabá. 2008. 97f. Dissertação (Mestrado em Educação). Programa de Pós-Graduação em Educação, Instituto de Educação da Universidade Federal de Mato Grosso. Cuiabá, MT, 2008. Disponível em: http://www.dominiopublico.gov.br/pesquisa/DetalheObraForm.do?select action=\&co obra=1 22194. Acesso em: 22 mar. 2021.

RIBEIRO, Wanda; PEREIRA, Juan Pablo de Jesus. Seven "myths" about the social participation of Waldorf graduates, São Paulo, Brazil, Oct. p. 1-17, 2007. Disponível em: https://www.ecswe.eu/wren/documents/seven_myths.pdf. Acesso em: 22 de mar. 2021.

SAB. Sociedade Antroposófica no Brasil —. 2019. Disponível em: http://www.sab.org.br/portal/antroposofia/sobre-rudolf-steiner/biografia-de-rudolf-steiner. Acesso em: 5 fev. 2020.

SETZER, Valdemar Waingort. Meu filho está terminando o ensino fundamental Waldorf: e agora? 2017. Disponível em: https://www.ime.usp.br/ vwsetzer/tirar-de-waldorf.html. Acesso em: 05 fev. 2020.

STEINER, Rudolf. A cultura atual e a educação waldorf: catorze palestras proferidas em Ilkley (Yorkshire, Inglaterra) de 5 a 17 de agosto de 1923. Tradução: Eleonore Olklaerner, Sérgio Correa, Jacira Cardoso. São Paulo: Antroposófica, Federação da Escolas Waldorf no Brasil (FEWB), 2014.

STEINER, Rudolf. A prática pedagógica: segundo o conhecimento científico- espiritual do homem. Tradução de Christa Glass. 2. ed. rev. e atual. São Paulo: Antroposófica, Federação das Escolas Waldorf no Brasil, 2013.

STEINER, Rudolf. Metodologia e didática no ensino waldorf: (A arte da Educação - II). O estudo geral do homem: uma base para a pedagogia. Tradução: Rudolf Lanz, Jacira Cardoso. 3. ed. Volume 2. São Paulo: Antroposófica, 2016.

STEINER, Rudolf. O Estudo geral do homem: uma base para a pedagogia. (A arte da Educação - I). Tradução: Rudolf Lanz, Jacira Cardoso. 6. ed. Volume 1. São Paulo: Antroposófica, 2018a.

STEINER, Rudolf. Os pontos centrais da questão social: aspectos econômicos, políticosjurídicos e espirituais da vida em sociedade. Tradução: Jacira Cardoso e Marco Bertalot-Bay. 2. ed. São Paulo: Antroposófica, 2018b. 